\title{
Dialogue From the Field
}

This section is devoted to contributions from the readership. These include articles, essays, commentary, and previously published chapters of special interest to the child development, early childhood intervention, and family support fields. The Editors and members of the Advisory Board welcome the participation of practitioners, researchers, and policy makers to continue "Dialogue From the Field."

\section{Shared Decision Making in Early Childhood Research: A Foundation for Successful Community-University Partnerships}

\author{
Faith Lamb-Parker \\ Columbia University \\ Daryl B. Greenfield \\ University of Miami \\ John W. Fantuzzo \\ University of Pennsylvania \\ Cheryl Clark \\ Early Childhood Consultant \\ Fairfax, VA \\ Kathleen Coyle Coolahan \\ Mathematica Policy Research, Inc.
}

\footnotetext{
The authors wish to thank the Administration on Children, Youth and Families/Head Start Bureau for its pioneering initiative to mandate the formation of partnerships between universities and the Head Start community as part of its grant application procedure. Without the mandate, this study could not have been conducted, but more importantly, the process of meaningful partnering between universities and Head Start would more than likely be far less developed. Special appreciation goes to Esther Kresh of the Bureau for believing that this study would make a contribution to the field. Finally, the authors would like to thank the Head Start university-community partnerships that participated in this study.

Correspondence should be sent to Faith Lamb -Parker, Mailman School of Public Health at . Columb ia University, 60 Haven Avenue B3, New York, NY 10032; flpl@ columbia.edu.
} 
The purpose of the paper was to examine the relationship between shared decision making and successful community-university research partnerships. Community partners and university researchers from 60 different partnership projects completed the Head Start Research Partnership Questionnaire that assessed the level of shared decision making of key partnership participants. The questionnaire also addressed the formation, maintenance, and focus of the partnership, community partners' levels of participation in the research, overall satisfaction with the partnership process, and the perceived value of the projects' findings and products. Respondents whose projects had a high level of shared decision making were compared to respondents whose projects had a low level of shared decision making. Results showed that high levels of shared decision making among partnership members led to more openly expressed and valued differences of opinion, better defined roles among partners, higher levels of concern for cultural sensitivity and for the protection of participant rights, as well as greater participation by community partners in all phases of the research project. Finally, partners with high levels of shared decision making reported higher levels of overall satisfaction with the research partnership project and found greater value in the research findings and products. Implications for future research also were discussed.

Traditionally, universities have claimed to be the repository of all knowledge with the university researcher as the only one qualified to pursue scientific inquiry. It is, therefore, not surprising that community agencies have been distrustful of research projects that are based on this presumption and positioned to advance only the prestige of the university. The traditional approach has created a considerable gap between research knowledge and practice. As Malouf and Schiller (1995) have observed, "research knowledge only sporadically finds its way into educational practice, even when the research has produced substantial knowledge related to problems of real-world importance" (p. 414).

In recent years, there has been a shift away from the traditional approach toward one that establishes research inquiry as a partnership process between university researchers and community-based service providers (Green \& McAllister, 1998; McCall, Green, Strauss, \& Groark, 1997; Sigel, 1997). The impetus for these changes comes from forces within both academia and community practice. On the university side, there is pressure from funding agencies to produce research that is more developmentally and culturally relevant to participants and more useful to practitioners and policy makers (e.g., Horowitz, 1990; Landesman Ramey \& Ramey, 1997; Lerner et al., 1996; Lewison \& Holliday, 1997; McCall, 1996; Sigel). On the community side, practitioners in education, health, and other human service delivery systems are being required by government funding agencies to use research methods to evaluate the efficacy of their services for diverse client populations (e.g., McHale et al., 1996; McWilliam, Desai, \& Greig, 1997). Service programs in early childhood intervention and family support, which are serving economically disadvantaged families and communities, are particularly challenged by the accountability demands of funding agencies. Service providers in these programs find it hard to justify spending precious agency resources on data collection and evaluation when they are struggling to meet the multiple and complex needs of low-income families (Landesman Ramey \& Ramey, 1997; Lerner et al.; Lewison \& Holliday; Sigel).

These contemporary forces have resulted in an increasing number of projects that use community-university partnerships as the framework for developing and implementing the research agenda. Over the last decade such partnership projects have spanned a broad array of disciplines including developmental psychology (Landesman, Ramey, \& Ramey, 1997); speech and language science (Wilcox, Hadley, \& Bacon, 1998); child psychology (Sigel, 1997); early childhood education and elementary education (Benton, Zath, Hensley, \& Waite, 1996; 
Kirschner, Dickinson, \& Blosser, 1996; Krasnow, 1997; Lewison \& Holliday,1997; Richmond, 1996; Webb, 1997); nursing-(McWilliam et al., 1997); social work (Lundy, Massat, Smith, \& Bhasin, 1996); psychiatry (Faulkner, 1989); school psychology (Dwyer \& Bernstein, 1998); and public health (Russos, Fawcett, Francisco, Berkley, \& Lopez, 1997).

As part of this growing trend in community-university partnerships, both the Administration on Children, Youth and Families (ACYF)/Head Start Bureau and the National Head Start Association (NHSA) convened panels to consider ways to improve the quality of early intervention programs through collaborative research efforts (National Head Start Association, 1990; U.S. Department of Health and Human Services, 1990; U.S. Department of Health and Human Services, 1993). Several major efforts to support community-university partnerships were initiated by these national institutions as a result of recommendations from these panels. Specifically for the NHSA, a research division and scholarly publication, the NHSA Dialog: A Research-to-Practice Journal for the Early Intervention Field was created (Lamb-Parker, 1999). Furthermore, the Administration on Children, Youth and Families/Head Start Bureau has sponsored five biennial national research conferences in early childhood and family support with a major goal of fostering partnerships among researchers, practitioners, and policy makers. Researchers, practitioners, and policy makers (e.g. Lamb-Parker, Hagen, Clark, \& Robinson, 1997; Lamb-Parker, Hagen, Robinson, \& Clark, 1999) have jointly presented sym-posia and workshops at these conferences, focusing on the partnership process. In addition, the ACYF/Head Start Bureau has funded a succession of research grant initiatives that involve a required partnership between university researchers and the Head Start community. During the period from 1990-1996, the Head Start Bureau funded 75 such "partnership" research projects.

These community-university research initiatives have been accompanied by a growing literature in scholarly journals addressing the community-university partnership process. At present this literature consists of articles that introduce conceptual frameworks of the partnership process. Common dimensions of the partnership process that have been identified in this literature include: (a) how the roles and responsibilities of various partners are defined; (b) how community partners actually participate in the research as partners; (c) the amount of time spent and. ways in which time is spent to "partner;" and (d) differing attitudes and beliefs held by members of the partnership about the goals, activities, and value of the research.

A considerable amount of attention in the literature has focused on "barriers" and "stumbling blocks" to successful partnering. Mistrust of the university researchers' intentions and apparent and real imbalance of power in the partnership are identified as major underlying dimensions of unsuccessful partnerships (Green \& McAllister, 1998; Faulkner, 1989; Lewison \& Holliday, 1997; Noffke, Clark, Palmeri-Santiago, Sadler, \& Shujaa, 1996; Reardon, 1995). These issues stem from traditional research approaches where research was done to "subjects" in community service settings with practitioners as bystanders and not with practitioners as participants. "Role rigidity," "professional territorialism," and an "aura of elitism" are terms used in the literature to describe how researchers exclusively dictate and control the research agenda (Faulkner; Lewison \& Holliday; McWilliam et. al., 1997). Researchers established power imbalances by claiming to have more knowledge and expertise than practitioners and using their research jargon and advanced-degree status to place themselves in a superior position in the partnership (Button, 1996; McHale et al., 1996; McWilliam et al.).

Shared decision making has been identified as an effective way of addressing power imbalances between researchers and practitioners (Button, 1996; Faulkner, 1989; Lewison \& Holliday, 1997; Noffke et al., 1996; McWilliam et al., 1997; Sigel, 1997; Turnbull, Friesen, \& Ramirez, 1998). According to Kagan and Rivera (1991), shared authority and decision making is essential for true collaboration. Shared decision making is described as making partners coequals in the research process. This is achieved by sharing ideas (Sigel; Susman, Koenigsberg, \& Bongard, 1989) and privileged knowledge (Kirschner et al., 1996); and by sharing control through a complex series of negotiations (McHale et al., 1996). It involves a process where 
partners voice the issues that are most important to them, and these issues guide a co-constructed research agenda. Setting the research agenda in partnership equalizes the power structure between researchers and community partners early in the partnering process, thus increasing the likelihood of greater meaningful participation by community members and a more productive research project (Krasnow, 1997).

Case studies have underscored the importance of shared decision making in the partnership process. Lundy and her colleagues (Lundy, Massat, Smith, \& Bhasin, 1996) found that all the basic decisions about the research had to be made jointly between researchers and practitioners to keep the partnership functioning. Conversely, others have reported that when partners did not share key decision-making roles early in the partnership process, significant conflicts and power struggles emerged that hindered the smooth operation of the research project (Landesman Ramey \& Ramey, 1997). However, to date, there are no empirical studies of the impact of shared decision making on the community-university partnership process.

The purpose of the present study was to examine the impact of shared decision making on the community-university research partnership process. As a result of the Head Start Bureau and NHSA efforts to foster research partnerships, there exists a sufficient body of Head Startsponsored research to study the relationship between levels of shared decision making and rel evant features of the research partnership process. The present study developed and used the Head Start-Research Partnership Questionnaire (HSRPQ; see Appendix) to survey researchers and Head Start practitioners representing 75 partnership projects funded by the ACYF/Head Start Bureau from 1990-1996. It was hypothesized that research projects that reported high levels of shared decision making would evidence significantly higher levels of successful partnership in terms of activities, time, attitudes and beliefs, and partnership outcomes than projects with low levels of shared decision making.

\section{METHODS}

\section{Participants}

Five types of partnership projects provided data for this study. Head Start-University Partnerships (18) were funded for 3 years to conduct research on a topic chosen by the local partnership team. Correlates of Positive Outcomes for Different Types of Head Start Children and Families (7) were similar to the Head Start-University Partnerships except funding was for 5 years, and the projects were required to be longitudinal, investigating the outcomes of Head Start children in elementary school. Early Head Start Partnerships (15) contributed data to a nationally coordinated study, but also conducted local research on Early Head Start programs serving families and children 03 years of age. The Head Start/Public School Transition Demonstration Project (31) was a partnership among Head Start, a local school system, and a research team to develop and evaluate the impact of providing Head Start-like services from kindergarten through third grade. Head Start Quality Research Centers (4) were funded to promote ongoing partnerships with the academic community and Head Start grantees.

Sample recruitment involved asking the principal investigators of each of the 75 total research initiatives to complete a brief Partnership Information form. This form asked for some basic information about the project as well as contact information for Head Start partners. In total, 60 responses were received by principal investigators. Individual researchers and Head Start partners were identified from these responses, and the Head Start-Research Partnership Questionnaire (HSRPQ) was mailed to these individuals. HSRPQs were received from 138 individuals representing 58 projects. These respondents represented 77\% (58 out of 75) of the Head Startfunded research projects from 1990-1996 that were charged at various levels to forge university/Head Start research partnerships.

The HSRPQs that were received represented 100\% of the Head Start-University Partnerships, $28 \%$ of the Correlates of Positive Outcomes projects, 67\% of the Early Head Start Partnerships, $77 \%$ of the Head Start Public School Transition Demonstration Projects, and 100\% of the Head 
Start Quality Research Centers. For the most part, response rates from each type of partnership project were similar except in the case of the Correlates of Positive Outcomes projects where only two of seven projects responded. The lower response rate was likely due both to the longitudinal design (5 years) and comple tion of these projects prior to administration of the survey. Children and families recruited through Head Start were followed into elementary school, diminishing Head Start partnerships beyond the 1st year of the study and requiring respondents to reconstruct perceptions that had occurred several years earlier.

Fifty-four percent of the respondents were university researchers and the remaining $46 \%$ were Head Start staff members. It should be noted that the number of partnership projects funded under each type varied considerably (only 4 Head Start Quality Research Centers versus 31 Head Start/Public School Transition Demonstration Projects); therefore, the respondents could not be equally distributed across project type. The purpose of this study, however, was not to compare differences across partnership types, but rather to investigate decision making within a mandated partnership model. Including all of the Head Start-mandated partnership projects provides us with a larger dataset to address this issue. In addition, instead of computing means; for each partnership project, data from all respondents were included in the. analyses. Such an approach could be problematic if a disproportionate number of respondents came from a small subset of projects; however, this turned out not to be the case. Of the 58 projects that responded, $68 \%$ included responses from at least one researcher and one Head Start staff member. In addition, only $8 \%$ of the projects had more than two researchers or more than two Head Start staff members who responded to the survey.

\section{Head Start-Research Partnership Questionnaire Development of the Measure}

An Ad-Hoc Partnership Task Force, a group of researchers, practitioners, and parents involved with Head Start research projects, developed the HSRPQ. First, the task force reviewed the research literature and grant proposals submitted to the ACYF to identify major themes and concepts related to conducting partnership-based research. These themes and concepts were organized into groups by experienced Head Start researchers and practitioners, and agreement was reached on key categories. Items with appropriate response formats were created to represent the categories. The two-page questionnaire was then administered to parent, researcher, and staff partners in two sites (one in Philadelphia and one in New York City) to assess its comprehension and content validity. The questionnaire was modified based on feedback from these groups.

\section{Description of the Measure}

The two-page questionnaire is comprised of seven distinct survey sections. Each section contains several items. All of these items address issues regarding the amount and quality of partnership associated with the research initiative. The first set of items asks the respondent to rate relative levels of decision-making influence on a 4point likert-type scale (None, Low, Moderate, and High) attributed to the Head Start Director, Policy Council representatives, university researchers, and participating Head Start and university research staff. The second and third sets of questions assess how regularly the partners meet (e.g., weekly, monthly, etc) and how the time was used in the 1 st and 2 nd years of the project, respectively. For the third section, respondents were asked to indicate the percentage of time during partnership meetings that was dedicated to addressing: (a) specific research issues (e.g., choice of measures, data collection, data analysis), (b) protecting participants' rights, (c) cultural sensitivity and values, (d) conflict resolution, (e) trust and consensus building, (f) barriers to project objectives, and (g) interpreting and disseminating results. The fourth section asked respondents to rate on a 4 point likert scale (None, Low, Moderate, and High) Head Start partners' level of participation in such tasks as designing the study, developing methods or measures, developing consent and recruitment procedures, and collecting and analyzing data. The fifth section contains items that ask respondents to rate how 
much they agree with nine statements about the formation and maintenance of the partnership on a 4-point scale (Disagree a Lot, Disagree a Little, Agree a Little, Agree a Lot). Finally, the sixth and seventh survey sections respectively involve ratings of overall satisfaction with the partnership on a 4point scale (Very Dissatisfied, Dissatisfied, Satisfied, Very Satisfied) and the overall value of the projects' findings and products (4-point scale from None to High). Internal consistency for the set of items in the decision-making section (1), participation section (4), and partnership formation and maintenance section (5) yield Cronbach alphas of .73, .73, and .76, respectively.

\section{Procedure}

The HSRPQ and an informed consent form were mailed to the identified researchers and practitioners from the 60 partnerships. Five weeks after the initial mailing, a reminder letter and duplicate questionnaire were mailed to those who had not returned their questionnaire.

\section{RESULTS}

\section{High and Low Decision-Making Groups}

The initial section of the survey asks respondents to rate the level of decision making of the Head Start Director, Policy Council representative, university researcher, participating Head Start staff, and participating university research staff. The involvement of each of these five persons/groups was rated on a 4point scale (None, Low, Moderate, High). An average rating across these five persons/groups was obtained by totaling the scores assigned to each person/group and dividing by five. This average rating reflected the level of shared decision making among partners. If only a few of a project's partners were involved in the decision process, then this average score would be low. Only if the majority of partners were scored high on decision-making would a project's average score be high. Next, the average decision-making rating was split at the median to form two groups of respondents representing relatively low and high levels of shared decision making. The median rating was moderate (3.0). The split yielded 34 respondents with average ratings less than 3.0 and 55 with ratings greater that 3.0. Additionally, respondents were divided into two categories of partners, Head Start and university researchers. A chi-square analysis was conducted to determine if there was a significant difference in the distribution of low and high decision-making ratings as a function of type of respondent. The chi-square analysis was not significant $\mathrm{c}^{2}(1, N=89)=2.4, p=1.2$. Therefore, levels of decision making for all respondents were used as the primary independent variable to maximize statistical power.

\section{Analytic Strategy}

The following data-analytic steps were undertaken to assess the relationship between levels of decision-making groups (high and low) and (a) the actual level of participation in the research by Head Start partners, (b) issues related to the formation and maintenance of the research partnership, and (c) how time was spent in partnership meetings. A multiple-analysis-of-variance statistic (MANOVA) was computed for each of the three distinct sets of survey questions corresponding to participation, partnership formation, and time utilization. MANOVAs were conducted as an omnibus test to determine overall group differences as a function of decisionmaking groups. If significant MANOVAs were found, univariate analyses were conducted for each survey item in the defined set of items to evaluate group differences. One-way analysis of variance analyses (ANOVAs) were conducted on the overall satisfaction and value survey items. For these ANOVAs, a Bonferroni correction was used to provide a more conservative criterion for significance.

\section{Participation of Head Start Partners in Research}

A one-way MANOVA across the set of participation survey questions revealed a significant overall difference between the Low and High Decision-Making groups, Wilks Lamda test of 
significance, $F(6,76)=6.4, p<.001$. Table 1 displays the descriptive statistics for each group of decision making. The univariate analyses indicated that the group that reported a high level of shared decision making reported that Head Start partners participated at a higher level in the design of the study, $F(1,81)=14.3, p<.001$; the development of informed consent and recruitment procedures, $F(1,81)=18.0, p<.001$; and the selection of measures, $F(1,81)=$ 29.3, $p<.001$, than the group that reported a low level of shared decision making. Additionally, the High Decision-Making group rated Head Start partners as being more involved in data collection, analysis, and interpretation than the Low Decision-Making group, $F(1,81)=5.3, p$ $<.05$. There were no significant group differences regarding the level at which parents, $F(1,81)$ $=.28, p=.65$, or Head Start staff, $F(1,81)=2.3, p=13$, participated as paid research assistants.

\section{Table 1.}

\section{Descriptive Statistics of Participation in Research Tasks by Head Start Partners for Groups of Low and High Levels of Decision Making}

\begin{tabular}{lll}
\hline Participation survey items & \multicolumn{2}{c}{ Level of decision making } \\
Low & High \\
\hline Head Start partners participated in the design of the study & & \\
$M$ & 2.0 & $2.9^{* * *}$ \\
$S D$ & 0.9 & 0.9 \\
Head Start partners jointly developed methods and measures & 1.8 & $3.0^{* * *}$ \\
$M$ & 0.8 & 0.9 \\
$S D$ & & \\
Head Start partners jointly developed the informed consent and & 2.4 & $3.3^{* * *}$ \\
procedures for recruitment of participants & 0.9 & 0.8 \\
$M$ & & \\
$S D$ & 2.0 & $2.6^{*}$ \\
Head Start partners were involved with data collection, data analysis, & 0.9 \\
and interpretation of the results & 1.0 & 1.9 \\
$M$ & & 1.9 \\
$S D$ & 1.1 & 1.1 \\
Parents participated in the research as paid research assistants & & 1.7 \\
$M$ & 1.9 & 0.9 \\
\hline$S D$ & 1.2 & \\
\hline
\end{tabular}

$* \mathrm{p}<.05, * * * \mathrm{p}<.001$

\section{Partnership Formation and Maintenance Issues}

Table 2 presents the descriptive statistics for the set of Partnership Formation and Maintenance Issue survey items. A significant MANOVA was found for group differences, Wilks Lamda test of significance, $F(9,63)=2.4, p<.05$. Univariate analyses showed that the High DecisionMaking group reported that partnership theory, $F(1,72)=5.7, p<.05$, and research, $F(1,72)=$ $8.1, p<.01$, influenced their research partnership to a greater degree than the Low DecisionMaking group. The High group also indicated that their partnership more openly expressed and valued differences of opinion among partners than the Low Decision-Making group, $F(1,72)=$ $4.2, p<.05$, and that the Head Start staff's participation in the research partnership contributed to their professional development, $F(1,72)=5.7, p<.05$. The Low Decision-Making group, on the other hand, indicated that they experienced more factors that inhibited the partnership process, $F$ $(1,72)=4.9, p<.05$, and that they, felt their partnership roles were more vague and ill-defined 
than the High Decision-Making group, $F(1,72)=9.2, p<.01$. No group differences were found regarding whether project participants received information regarding the results, $F(1,72)=1.9$, $p=.17$, or whether partnership issues emerged that were not anticipated, $F(1,72)=.05, p=.83$. Also the groups did not differ in their report of whether the partnership contributed to more culturally sensitive services, $F(1,72)=1.9, p=.17$.

\section{Time Distribution of Research-Partnership Activities}

Over $96 \%$ of the respondents reported that their partnership teams held regular meetings to discuss different facets of the research. Regular meetings were reported as occurring annually for $6 \%$ of the respondents, monthly for $58 \%$, quarterly for $22 \%$, and weekly for $14 \%$. A MANOVA in Year 1 of the project across five different types of research tasks indicated that there was a significant difference between the Low and High Decision-Making groups, Wilks Lamda test of significance, $F(5,44)=3.7, p<.01$ (see Table 3). Univariate assessments showed that the High Decision-Making group. was spending a higher percentage of its meeting time discussing issues related to protecting the rights of participants, $F(1,48)=4.3, p<.05$ and those involving cultural sensitivity and values, $F(1,48)=8.5, p<.01$. In Year 1 , there were no reported differences in time spent on specific research methods, $F(1,48)=1.4, p=.24$; barriers, $F(1,48)$ $=1.7, p=.20$; or discussing research results, $F(1,48)=.14, p=.56$.

Analyses for Year 2 also found a significant MANOVA for group differences, Wilks Lamda test of significance, $F(5,46)=5.5, p<.001$ (see Table 3). In Year 2, univariate analyses revealed that the High Decision-Making group spent significantly more time on specific research methods (e.g. choice of measure and procedures) than the Low Decision-Making group, $F(1,50)$ $=6.3, p<.05$, and continued to spend more time addressing ways to protect the rights of participants, $F(1,50)=5.0, p<.05$. The Low Decision-Making group reported spending more time in Year 2 discussing barriers to meeting project objectives than the High Decision-Making group reported, $F(1,50)=12.0, p<.005$. There were no significant group differences reported in time spent on cultural sensitivity and vahes, $F(1,50)=.7, p=.4$, and research results, $F(1$, $50)=.01, p<.9$ in Year 2 .

Table 2.

\section{Descriptive Statistics of Partnership Formation and Maintenance Issues for Groups of Low and High Levels of Decision Making}

\section{Formation and maintenance survey items}

\section{Level of decision making}

Low

High

Published theories or principles of partnership influenced our research partnership.

$\mathrm{M}$

$S D$

Published research on the partnership process influenced our research partnership.

$M$

$S D$

Roles of the partnership members regarding project objectives were vague and ill-defined.

$M$

$S D$

There were factors that inhibited the partnership process.
2.1

1.0

1.9

0.9

2.4

1.1

2.8
2.6*

1.0

$2.6^{* *}$

1.0

$1.7 * *$

1.0 
$S D$

Differences of opinion among partners were openly expressed and valued.

$M$

$S D$

Project participants received information about the research results.

$M$

$S D$

Major partnership issues emerged that were not originally anticipated.

$M$

$S D$

Participating in the research activities contributed to the professional development of members of the Head Start staff.

$M$

$S D$

The partnership contributed to more culturally sensitive services.

$M$

$S D$
1.2

1.0

$3.0 \quad 3.4^{*}$

$0.9 \quad 0.6$

$3.2 \quad 3.4$

$0.9 \quad 0.8$

$2.8 \quad 2.8$

$1.2 \quad 1.2$

$2.9 \quad 3.5^{*}$

$0.8 \quad 0.8$

$2.6 \quad 3.0$

$1.0 \quad 0.9$

$* ' \mathrm{p}<.05, \mathrm{p}<.01, * * * \mathrm{p}<.001$

Table 3.

Descriptive Statistics on Time Distribution in Year 1 and Year 2 of Project for Groups of Low and High Levels of Decision Making

\begin{tabular}{|c|c|c|c|c|}
\hline \multirow[t]{2}{*}{ Research task } & \multicolumn{2}{|c|}{$\begin{array}{c}\text { Year } 1 \\
\text { Level of decision making }\end{array}$} & \multicolumn{2}{|c|}{$\begin{array}{c}\text { Year } 2 \\
\text { Level of decision making }\end{array}$} \\
\hline & Low & High & Low & High \\
\hline \multicolumn{5}{|c|}{$\begin{array}{l}\text { Specific research issues (choice of } \\
\text { measures, data collection, and analysis) }\end{array}$} \\
\hline$M$ & 2.0 & 2.3 & 1.7 & $2.4 *$ \\
\hline$S D$ & 0.9 & 1.0 & 0.9 & 1.0 \\
\hline \multicolumn{5}{|c|}{ Protecting rights of participants } \\
\hline$M$ & 1.4 & $2.2 *$ & 1.2 & $1.7^{*}$ \\
\hline$S D$ & 0.7 & 1.1 & 0.5 & 0.9 \\
\hline \multicolumn{5}{|c|}{ Cultural sensitivity and values } \\
\hline$M$ & 1.4 & $2.3^{* *}$ & 1.5 & 1.9 \\
\hline$S D$ & 0.6 & 1.0 & 0.7 & 1.0 \\
\hline \multicolumn{5}{|c|}{ Barriers to project's objectives } \\
\hline$M$ & 2.0 & 1.8 & 2.4 & $1.7 * *$ \\
\hline$S D$ & 1.0 & 1.0 & 0.8 & 0.7 \\
\hline \multicolumn{5}{|c|}{$\begin{array}{l}\text { Research results (interpreting and } \\
\text { disseminating results) }\end{array}$} \\
\hline$M$ & 1.4 & 1.3 & 1.7 & 1.7 \\
\hline$S D$ & 0.7 & 0.6 & 0.9 & 0.9 \\
\hline
\end{tabular}

$* \mathrm{p}<.05, * * \mathrm{p}<.01$

\section{Overall Satisfaction and Value}

ANOVA results revealed significant differences between the High and Low Decision-Making groups on both their overall satisfaction with the research. partnership project and their estimation of the value of the research findings and products. The High group's mean (standard deviation) satisfaction rating was 3.6 (.50) which was significantly higher than the mean of $3.2(.70)$ for the 
Low group, $F(1,85)=4.6, p<.05$. Likewise, the High group's mean (standard deviation) value rating was $3.5(.54)$ which was significantly higher than the mean of $3.1(.70)$ for the Low group, $F(1,83)=6.1, p<.05$.

\section{DISCUSSION}

The present study was conducted as an initial attempt to empirically explore various facets of the process of partnering between university researchers, and their community partners. Although there has been much interest in this topic, publications to date have been limited to discussions of conceptual frameworks for successful partnerships (e.g., Button, 1996; Green \& McAllister,1998; Krasnow, 1997; Lewison \& Holliday, 1997) and case studies: (e.g., Krasnow; Lewison \& Holliday; McWilliam et al., 1997; Richmond,. 1996; Weinberg \& Erickson, 1996; Wilcox, Hadley, \& Bacon, 1998). The present study represents the first empirical examination of the process of partnering in a research context and includes the points of view of community and research stakeholders.

The past decade has witnessed a shift in university research conducted in community settings. The traditional model of viewing these settings as a source of subjects and data to further the university investigator's research agenda is being replaced by a partnership model where practitioners are co-decision makers in the development and implementation of the research project. The purpose of the present paper was to use the HSRPQ to examine the hypothesis that shared decision making is associated with major ele ments of successful community-university research partnerships. The HSRPQ development was informed by the community-researcher partnership literature and by feedback obtained from researchers and practitioners with partnership experience. The HSRPQ items represented seven distinctive categories of issues relevant to partnership formation. The HSRPQ was used to compare respondents who reported that their projects had a high level of shared decision making among partnership members with respondents who reported relatively low levels of shared decision making.

Significant differences occurred between groups with respect to the major partnership foci in the 1 st and 2nd years of their research grant. Respondents involved in partnerships with high levels of shared decision making spent a greater proportion of their partnership meeting time during the 1 st year discussing issues related to protection of participants' rights and sensitivity to participants' culture and values. In the 2nd year, projects with high levels of shared decision making devoted more time to discussing specific research issues such as the choice of measures and procedures. Projects with low levels of shared decision making, on the other hand, spent more time during their 2nd year dealing with problems that impeded the project's progress.

Congruent with reported differences in time allocation, partners in projects with high levels of shared decision making also reported that differences of opinion were more valued and more openly expressed than respondents from projects where decision making was not shared. In contrast, respondents from projects where decision making was not shared reported experiencing more factors that inhibited the partnership process.

These differences suggest that shared decision making allowed the community partners to voice their high priority concerns early on in the project (Lewison \& Holliday, 1997). Noffke (1996) and others (e.g., Benton et al., 1996; Lundy et al., 1996; Richmond, 1996) stress dealing with sensitive issues with all partners early and often. However, without shared decision making, sensitive issues that are more critical to successful partnering may not be resolved early in the partnership process, potentially impeding the subsequent research activities. It is likely that university researchers were less sensitive to issues of participants' rights and culture at the outset of the research grant's process since they addressed these issues with their university Internal Review Boards prior to the submission of a research proposal. Therefore, they probably were less likely to place these issues as high priority and more likely to forge ahead with the specific research tasks. Partnerships with shared decision making provided community partners opportunities to raise these issues early in the partnership process. The results suggest that 
minimizing the role of community partners in decision making and failure to make participants' rights and sensitivities a high priority early on are associated with a less successful implementation of research agenda.

Respondents from projects with high levels of shared decision making reported that published theory and research on the partnership process influenced their partnership. This was not the case for respondents from projects with low levels of shared decision making, who instead reported that roles of the partnership members regarding project objectives were vague and ill-defined. It is also noteworthy that respondents from projects with high levels of shared decision making to a significantly greater degree reported that participation in their partnership contributed to the professional development of the community staff members.

Participation in decision making, therefore, seems to allow for a free exchange of ideas and opinions that may better acquaint community partners with information related to the partnership process itself as well as the "mys teries" of research. Moreover, sharing knowledge on partnership formation from the research literature and exchanging ideas about partnering and research methods may have helped community members define their roles more specifically. This exchange also may have facilitated their involvement in the research process resulting in benefits to their professional growth and development (Faulkner, 1989; Kagan \& Rivera, 1991; Krasnow, 1997; McWilliam et al., 1997; Weinberg \& Erickson, 1996).

High levels of shared decision making among partners were not only reflected in important differences in partnership priorities, but also associated with a higher degree of involvement among community partners in key research tasks. Partnership projects with high levels of shared decision making reported significantly higher levels of involvement among Head Start partners in specific research activities (i.e., the design of the study, development of the informed consent, selection of measurement instruments, recruitment procedures, data collection, data analysis, and the interpretation of research findings). An important goal of university-community partnerships is active participation by community partners in all phases of the research endeavor (U.S. Department of Health and Human Services, 1990). Our data suggest that high shared decision making during the early phases of the project was associated with high levels of involvement for Head Start staff.

Finally, the results from the present study showed that respondents from partnership projects with high levels of shared decision making reported a high level of satisfaction with the research partnership. In addition, these respondents found the research findings and products to be of greater value to them than those who experienced low levels of shared decision making. These findings are consistent with the case studies that demonstrated that shared decision making, although tremendously time consuming, helped establish strong, solid foundations of trust and mutual respect. Those in turn led to positive outcomes for the partnership itself, for the research project, and for the professional and personal development of the members (Benton et al., 1996; Button, 1996; Krasnow, 1997; Lamb-Parker, Abdul-Kabir, Fantuzzo, Young, Clark, \& Peay, 1995; McWilliam et al., 1997; Weinberg \& Erickson, 1996).

Limitations of the study, however, should be noted. First, all data came from Head StartUniversity partnerships where the initial relationship between partners was mandated by the funding source. However, an increasing number of funding sources available both to researchers and community agencies are adopting a partnership model for research and evaluation. Second, analyses were conducted only on partners who returned the survey. Since nonparticipation in the survey was largely due to researchers who did not respond to our initial query and not from participants who received the survey, it is likely that less successful partnerships were underrepresented in the survey results. Finally, the data were retrospective and correlational in nature, precluding definitive causal relationships among variables. It is note worthy to mention here that the variability of the responses from those who returned the survey made it possible to conduct appropriate and meaningful analyses, in spite of the possibility that the sample was made up of those who felt that they had participated in a "good" partnership. 


\section{IMPLICATIONS}

The present study is the first empirical examination of Head Start/research university partnership practices. Even with its limitations and qualifications, the findings of this study have significant implications for policy and practice. These data support both the ACYF/Head. Start Bureau's and the NHSA's policies underscoring the importance of conducting research in Head Start based on open, ongoing, two-way exchanges between university researchers and Head Start staff and parents (National Head Start Association, 1990; U.S. Department of Health and Human Services, 1990; U.S. Department of Health and Human Services, 1993). Specifically, they support $\mathrm{ACYF} / \mathrm{Head}$ Start Bureau's recent grant initiatives that have required a formal acknowledgement of a partnership agreement between the Head Start staff and Parent Policy Council and the university researchers as a condition of funding. The present findings suggest that the granting agency may need to go beyond the requirement of an initial partnership agreement and pay close attention to the quality of the developing research partnerships. Our findings suggest that early attempts to share decision making regarding the research agenda were associated with more efficient and beneficial uses of grant funds. Participant reports suggest that research conducted in the context of genuine partnerships may result in more valid research products that are more readily translatable into Head Start practice and policy.

There are two fundamental realities that support this policy position: First, there is no "one" Head Start prototype, and second, many of our research methods were not developed or empirically tested for the populations of children and families that Head Start serves. There are many configurations of Head Start services that reflect the varying sets of needs of the diverse populations that Head Start is serving nationally. A key question for policymakers articulated in the "Blueprint" Panel report is, "Which Head Start practices maximize benefits for children and families with different characteristics under what types of circumstances?" (U.S. Department of Health and Human Services, 1990). As a result of this broad question, policymakers have charged Head Start researchers to increase their level of cultural sensitivity to special subpopulations in Head Start. Moreover, measures and procedures developed for White middle class populations cannot be simply applied to these populations without careful consideration and empirical testing. The inappropriate application of norms derived from the study of mainstream children to nonmainstream children has made the latter group vulnerable to being characterized as deviant, rather than different (Spencer, 1990). Since the demography of our child population is becoming increasingly diverse (Takanishi \& DeLeon, 1994), we must empirically test the validity of the existing applications to minority preschool children and identify salient cultural variables that should inform future research. In addition to being guided by theory in the development of our research, we also must consider how differences in culture may affect the significance and meaning of our proposed research agenda for our African American, Asian. American, American Indian, and Hispanic Latino partners (Garcia Coll et al., 1996; Spencer \& Dupree, 1996).

Lastly, the data suggest that early in the research process concrete procedures should be in place to actively encourage and facilitate practitioners and parents at the local level to participate more fully as partners in research. This may take the form of special training to identify common objectives of the research and to establish a common language for the fundamental research activity. These and other issues need to be explored in future empirical research that focuses more directly on pathways between 1st year activities, decision making, and the success of the research enterprise. Such studies should include a wider range of research partnership types including those in which the relationship between researchers and practitioners is not mandated.

One of the potential benefits of involving community partners in all phases of the research project is that the research will translate more quickly and easily into practice. This has not been true of most educational research, even when the research has produced substantial knowledge related to problems of reatworld importance (Malouf \& Schiller, 1995). Our data suggest that a high level of shared decision making among research and community partners may be a key to 
facilitating such application for the ultimate benefit of not only researchers and community partners, but also program participants. Such a pattern of involvement should produce both the motivation and ability to apply these relevant findings to program practices. Since research is an ongoing, iterative process, community partners' satisfaction as a result of full partnership participation in the research process should also help to insure continued research collaboration.

\section{REFERENCES}

Benton, J., Zath, R. C., Hensley, F., \& Waite, D. (1996). Negotiating schooluniversity partnerships: Participants' voices in co-reform. The Urban Review, 28(3), 257-278.

Button, K. (1996). Enabling schooluniversity collaborative research: Lessons learned in professional development schools. Journal of Teacher Education, 47(1), 16-20.

Dwyer, K. P., \& Bernstein, R. (1998). Mental health in the schools: Linking islands of hope in a sea of despair. School Psychology Review, 27(2), 277-286.

Faulkner, L. R. (1989). Oregon's state-university collaboration in national context. In J. D. Bloom (Ed.), State-university collaboration: The Oregon experience (pp. 29-39). San Francisco: Jossey-Bass.

Garcia Coll, C., Lamberty, G., Jenkins, R., McAdoo, H., Crnic, K., Wasik, B., \& Vazquez Garcia, H. (1996). An integrative model for the study of developmental competencies in minority children. Child Development, 67,1891-1914.

Green, B. L., \& McAllister, C. (1998). Theory-based, participatory evaluation: A powerful tool for evaluating family support programs. Zero to Three, 18(4), 30-37.

Horowitz, F. D. (1990). The multiple partnership: Scientist, university, agency, and government. American Psychologist, 45(1), 51-53.

Kagan, S. L., \& Rivera, A. M. (1991). Collaboration in early child care and education: What can and should we expect? Young Children, 47(1), 51-56.

Kirschner, B. W., Dickinson, R., \& Blosser, C. (1996). From cooperation to collaboration: The changing culture of a school/university partnership. Theory Into Practice, 35(3), 205-213.

Krasnow, M. H. (1997, March). Learning to listen, talk, and trust: Constructing collaborations. Paper presented at the annual meeting of the American Educational Research Association, Chicago, IL.

Lamb-Parker, F. (1999, Spring). Letter from the editor. NHSA Dialog: A Research-to-Practice Journal for the Early Intervention Field, 2(2), 191.

Lamb-Parker, F., AbdulKabir, S., Fantuzzo, J., Young, S., Clark, B., \& Peay, L. (1995, April). Head Start/researcher partnerships: How to build them and use them to benefit Head Start staff and parents. Paper presented at the National Head Start Association's 22nd Annual Training Conference,

Washington, DC

Lamb-Parker, F., Hagen, J., Clark, C., \& Robinson, R. (Eds.). (1997). Making a difference for children, families and communities: Partnerships among researchers, practitioners and policy makers. Summary of Conference Proceedings. Washington, DC: Administration on Children, Youth and Families (DHHS).

Lamb-Parker, F., Hagen, J., Robinson, R., \& Clark, C. (Eds.). (1999). Children and families in an era of rapid change: Creating a shared agenda for researchers, practitioners and policy makers. Summary of Conference Proceedings. Washington, DC: Administration for Children, Youth and Families (DHHS).

Landesman Ramey, S., \& Ramey, C. T. (1997). The role of universities in child development. In H. J. Walberg \& O. Reyes (Eds.), Children and youth: Interdisciplinary perspectives: Vol. 7. Issues in children's and families' lives (pp. 13-44). Thousand Oaks, CA: Sage.

Lerner, R. M., Ostrom, C. W., Miller, J. R., Votruba, J. C., von Eye, A., Hoopfer, L. C., et al. (1996). Training applied developmental scientists for community outreach: The Michigan State University model of integrating science and outreach for children, youth, and 
families. In I. E. Sigel.(Series Ed.) \& C. B. Fisher, J. P Murray, \& I. E. Sigel (Vol. Eds.), Applied developmental science: Vol. 13. Graduate training for diverse disciplines and educational settings: Advances in applied developmental psychology (pp. 163-188). Norwood, NJ: Ablex.

Lewison, M., \& Holliday, S. (1997, Winter). Control, trust, and rethinking traditional roles: Critical elements in creating a mutually beneficial university-school partnership. Teacher Education Quarterly, 24(1), 105-126.

Lundy, M., Massat, C. R., Smith, J., \& Bhasin, S. (1996). Constructing the research enterprise: Building research bridges between private agencies, public agencies and universities. Journal of Applied Social Sciences, 20(2), 169-176.

McCall, R. B. (1996). The concept and practice of education, research, and public service in university psychology departments. American Psychologist, 51 (4), 379-388.

McCall, R., Green, B. L., Strauss, M. S., \& Groark, C. J. (1997). Issues in community-based research and evaluation. In I. E. Sigel \& A. K. Renninger (Vol. Eds.), Handbook of child psychology: Vol. 4. Child psychology in practice (pp. 955-997). New York: Wiley.

McHale, S. M., Crouter, A. C., Fennelly, K., Tomascik, C. A., Updegraff, K. A., Graham, J. E., et al. (1996). Community-based interventions for young adolescents: The Penn State PRIDE Project. Journal of Research on Adolescence, 6(1), 23-26.

McWilliam, C. L., Desai, K., \& Greig, B. (1997). Bridging town and gown: Building research partnerships between community-based professional providers and academia. Journal of Professional Nursing, 13(5), 307-315.

Malouf, D. B., \& Schiller, E. P. (1995). Practice and research in special education. Exceptional Children, 61, 414-424.

National Head Start Association (1990, May). Head Start: The nation's pride, a nation's challenge. Recommendations for Head Start in the 1990s. The report of the Silver Ribbon Panel. Alexandria, VA: Author.

Noffke, S. E., Clark, B. G., Palmeri-Santiago, J., Sadler, J., \& Shujaa, M. (1996). Conflict, learning, and change in a school/university partnership: Different worlds of sharing. Theory Into Practice, 35(3), 165-172.

Reardon, K. M. (1995). Creating a community/university partnership that works: The case of the East St. Louis Action Research Project. Metropolitan Universities, 5(4), 47-59.

Richmond, G. (1996). University/school partnerships: Bridging the culture gap. Theory Into Practice, 35(3), 214-218.

Russos, S., Fawcett, S. B., Francisco, V. T., Berkley, J. Y., \& Lopez, C. M. (1997). In P. A. Lamal (Ed.), Cultural contingencies: Behavior analytic perspectives on cultural practices (pp. 87-106). Westport, CT: Greenwood.

Sigel, I. E. (1997). Practice and research: A problem in developing communication and cooperation. In I. E. Sigel \& A. K. Renninger (Vol. Eds.), Handbook of child psychology: Vol. 4. Child psychology in practice (5th ed., pp. 1113-1132), New York: Wiley.

Spencer, M. B. (1990). Development of minority children: An introduction. Child Development, 61, 267-269.

Spencer, M. B., \& Dupree, D. (1996). African American youths' ecocultural challenges and psychosocial opportunities: An alternative analysis of problem behavior outcomes. In D. Cicchetti \& S. Toth (Eds.), Adolescence: Opportunities and challenges. Rochester symposium on developmental psychopathology, (7th ed., pp. 259-282). Rochester, NY: University of Rochester Press.

Susman, M., Koenigsberg, J., \& Bongard, B. (1989). The business of ivory tower research: Paradigms for university-corporate partnerships. Journal of Business and Psychology, 4(2), 251-58. 
Takanishi, R., \& DeLeon, P. H. (1994). A Head Start for the 21st century. American Psychologist, 49(2), 120-122.

Turnbull, A. P., Friesen, B. J., \& Ramirez, C. (1998) Participatory action research as a model for conducting family research. JASH, 23(3), 178-188.

U.S. Department of Health and Human Services (1990, September). Head Start research and evaluation: A blueprint for the future. Recommendations of the Advisory Panel for Head Start Evaluation Design Project. Washington, DC: Administration on Children, Youth and Families.

U.S. Department of Health and Human Services (1993, December). Creating a 21st century Head Start: Final report of the Advisory Committee on Head Start Quality and Expansion. Washington, DC: Administration on Children, Youth and Families.

Webb, N. C. (1997). Working with parents from cradle to preschool: A university collaborates with an urban public school. Young Children, 52(4), 15-19.

Weinberg, R. A., \& Erickson, M. F. (1996). Minnesota's Children, Youth, and Family Consortium: A university-community collaboration. Journal of Research on Adolescence, 6(1), 37-53.

Wilcox, M. J., Hadley, P. A., \& Bacon, C. K. (1998). Linking science and practice in management of childhood language disorders: Models and problem-solving strategies. Topics in Language Disorders, 18(2), 10-22.

\section{APPENDIX}

\section{Head Start-Research Partnership Questionnaire}

1. Rate the level of decision making for each of the following partners:

\begin{tabular}{|l|c|c|c|c|}
\hline & $\begin{array}{c}\text { None / only } \\
\text { advisory }\end{array}$ & Low & Moderate & High \\
\hline Head Start Director & 1 & 2 & 3 & 4 \\
\hline Policy Council representatives & 1 & 2 & 3 & 4 \\
\hline University researcher & 1 & 2 & 3 & 4 \\
\hline Participating Head Start staff & 1 & 2 & 3 & 4 \\
\hline Participating university research staff & 1 & 2 & 3 & 4 \\
\hline
\end{tabular}

2. Did you have regular partnership meetings? $\quad$ Yes No

\begin{tabular}{|l|l|l|l|c|c|}
\hline $\begin{array}{l}\text { If yes, indicate which of the following } \\
\text { best represents how regularly you met } \\
\text { during each year of the project: }\end{array}$ & Year 1 & Year 2 & Year 3 & $\begin{array}{c}\text { Year 4 } \\
\text { (if applicable) }\end{array}$ & $\begin{array}{c}\text { Year 5 } \\
\text { (if applicable) }\end{array}$ \\
\hline $\begin{array}{l}\text { W=weekly, M=monthly, } \\
\mathbf{Q}=\text { quarterly, } \mathbf{A}=\text { =annually }\end{array}$ & & & & & \\
\hline
\end{tabular}


3. Indicate which of the following best represents the amount of time spent on the following tasks at partnership meetings during each year of the project:

$$
\mathbf{1}=0-25 \%, \mathbf{2}=26-49 \%, \mathbf{3}=50-74 \%, \mathbf{4}=75-100 \%, \mathbf{X}=\text { cannot remember }
$$

\begin{tabular}{|l|l|l|l|l|l|}
\hline \multicolumn{1}{|c|}{ Tasks } & Year 1 & Year 2 & Year 3 & $\begin{array}{c}\text { Year 4 } \\
\text { (if applicable) }\end{array}$ & $\begin{array}{c}\text { Year 5 } \\
\text { (if applicable) }\end{array}$ \\
\hline $\begin{array}{l}\text { a) Specific research issues (choice of } \\
\text { measures, data, collection, and } \\
\text { analysis) }\end{array}$ & & & & & \\
\hline b) Protecting rights of participants & & & & & \\
\hline c) Cultural sensitivity and values & & & & & \\
\hline $\begin{array}{l}\text { d) Differences among partners/conflict } \\
\text { resolution }\end{array}$ & & & & & \\
\hline $\begin{array}{l}\text { e) Issues of trust and consensus building } \\
\text { and strengths and capacities of } \\
\text { partners }\end{array}$ & & & & & \\
\hline f) Barriers to project's objectives & & & & & \\
\hline g) Research results(interpreting and \\
disseminating results)
\end{tabular}

4. Indicate the level of participation in the actual research tasks by Head Start partners across the following:

\begin{tabular}{|l|c|c|c|c|}
\hline Tasks & None & Low & Moderate & High \\
\hline a) Head Start partners participated in the & 1 & 2 & 3 & 4 \\
design of the study & 1 & 2 & 3 & 4 \\
\hline $\begin{array}{l}\text { b) Head Start partners jointly develop } \\
\text { methods or measures for the study. }\end{array}$ & 1 & 2 & 3 & 4 \\
\hline $\begin{array}{l}\text { c) Head Start partners jointly developed the } \\
\text { informed consent and recruitment of } \\
\text { participants procedures. }\end{array}$ & 1 & 2 & 3 & 4 \\
\hline $\begin{array}{l}\text { d) Head Start partners were involved with } \\
\text { the data collection, data analysis, and } \\
\text { interpretation of results. }\end{array}$ & 1 & 2 & 3 & 4 \\
\hline e) Parents participated in the research as \\
research assistants (paid).
\end{tabular}

5. Indicate how much you agree with each of the statements about your Head Start research partnership.

\begin{tabular}{|l|c|c|c|c|}
\hline Statements about the partnership: & $\begin{array}{c}\text { Disagree } \\
\text { a lot }\end{array}$ & $\begin{array}{c}\text { Disagree } \\
\text { a little }\end{array}$ & $\begin{array}{c}\text { Agree } \\
\text { a little }\end{array}$ & $\begin{array}{c}\text { Agree } \\
\text { a lot }\end{array}$ \\
\hline $\begin{array}{l}\text { a) Published theories or principles of } \\
\text { partnership influenced our research } \\
\text { partnership. }\end{array}$ & 1 & 2 & 3 & 4 \\
\hline $\begin{array}{l}\text { b) Published research on the partnership } \\
\text { process influenced our research } \\
\text { partnership. }\end{array}$ & 1 & 2 & 3 & 4 \\
\hline $\begin{array}{l}\text { c) Prior to this research project, I had very } \\
\text { little experience with research partnership }\end{array}$ & 1 & 2 & 3 & 4 \\
\hline
\end{tabular}




\begin{tabular}{|c|c|c|c|c|}
\hline $\begin{array}{l}\text { d) Prior to funding, partners developed a } \\
\text { shared vision and project goals. }\end{array}$ & 1 & 2 & 3 & 4 \\
\hline $\begin{array}{l}\text { e) Roles of the partnership members } \\
\text { regarding project objectives were vague } \\
\text { and ill defined. }\end{array}$ & 1 & 2 & 3 & 4 \\
\hline $\begin{array}{l}\text { f) There were factors that inhibited the } \\
\text { partnership process. }\end{array}$ & 1 & 2 & 3 & $\overline{4}$ \\
\hline $\begin{array}{l}\text { g) Differences of opinion among partners } \\
\text { were openly expressed and valued. }\end{array}$ & 1 & 2 & 3 & $\overline{4}$ \\
\hline $\begin{array}{l}\text { h) Project participants received information } \\
\text { about the results of the research }\end{array}$ & 1 & 2 & 3 & $\overline{4}$ \\
\hline $\begin{array}{l}\text { i) Major partnership issues emerged that } \\
\text { were not originally anticipated. }\end{array}$ & 1 & 2 & 3 & $\overline{4}$ \\
\hline $\begin{array}{l}\text { j) Parent involvement in their child's Head } \\
\text { Start/Early Head Start experience was not } \\
\text { affected by any of the research activities. }\end{array}$ & 1 & 2 & 3 & $\overline{4}$ \\
\hline $\begin{array}{l}\text { k) Participating in the research activities } \\
\text { contributed to the professional develop- } \\
\text { ment of members of Head Start staff. }\end{array}$ & 1 & 2 & 3 & 4 \\
\hline $\begin{array}{l}\text { 1) The research findings were unrelated to } \\
\text { the Head Start partners' service provider } \\
\text { issues. }\end{array}$ & 1 & 2 & 3 & 4 \\
\hline $\begin{array}{l}\text { m) The partnership contributed to more } \\
\text { culturally sensitive services }\end{array}$ & 1 & 2 & 3 & $\overline{4}$ \\
\hline $\begin{array}{l}\text { n) The research findings were interesting but } \\
\text { they have not been used to develop new } \\
\text { training methods, materials, and practice }\end{array}$ & 1 & 2 & 3 & 4 \\
\hline
\end{tabular}

6. Rate your overall satisfaction with the Head Start/University Research Project. (Circle)
Very dissatisfied
Dissatisfied
Satisfied
Very satisfied

7. Rate the overall value of this research's findings and products. (Circle)
None
Low
Moderate
High 


\title{
Truths Converging: Empirical Support for Intuitive Understanding
}

\author{
Ann P. Turnbull \\ Jean Ann Summers \\ Betsy Santelli \\ Ursula Markey \\ University of Kansas
}

In an article about participatory action research published in 1998, one of the authors of this commentary remarked that there was no empirical documentation of the efficacy of research in which the various stakeholders are involved throughout the process of planning and conducting the study (Turnbull, Friesen, \& Ramirez, 1998). Now, we are delighted to see that Faith LambParker et al. have gone a long way toward correcting this deficit. We should also congratulate the ACYF/Head Start Bureau for the creation of the communityuniversity partnership funding initiatives, with ther accompanying requirements for researchers, practitioners, and parents to develop and carry out research in partnership. These community-university partnership funding initiatives created the sufficient and appropriately similar pool of partnerships necessary for an empirical study to occur.

This survey of 60 community-university partnerships is an affirmation for those who have advocated shared decision making in the conduct of research. The creation of a strategy to measure the degree to which decision making is shared (by averaging ratings of degree of participation across five groups) is in itself a contribution to the field. But the best news is that the results of this study suggest that a high level of shared decision making is associated with a number of beneficial characteristics of effective partnerships, including a greater sense of involvement among the partners in all phases of the study, a greater sense of satisfaction with the research process, and a perception by the participants that the research was valuable to them. Participants in partnerships with high levels of shared decision making appeared to spend more time working on issues such as protecting participant rights and sensitivity to participants' culture in the 1st year, and in the 2nd year spent time on more concrete, "down to business" issues such as specific research and choice of measures and procedures. In contrast, projects with low levels of shared decision making were spending more time in their 2nd year working on problems that were impeding the progress of the project. These findings suggest that initial investment of time and effort into forging a meaningful process-always time consuming-may, in the end, be more than worth it in terms of effective and timely completion of the project.

Correspondence should be addressed to Ann P Turnbull, Beach Center on Disability, University of Kansas, 3111 Haworth Hall, Lawrence, Kansas 66045; e-mail: tumbull@ku.edu. 
This is not to say that shared decision making is easy to achieve--far from it! In our own partnership experience involving the Beach Center on Disability at The University of Kansas (a university-based center focusing on research, technical assistance, and policy analysis related to disability and family issues) and the Grassroots Consortium on Disability (a national coalition of community-based, parent-directed family support and information programs serving culturally and linguistically diverse families who have children with disabilities), we learned early that good intentions were insufficient in overcoming the barriers that typically exist between the research world and families living in traditionally underserved communities (Markey, Santelli, \& Turnbull, 1998; Santelli, Markey, Johnson, Turnbull, \& Turnbull, 2001). Those of us at the university were not prepared for the anger built-up over decades that existed in the hearts and minds of families from underserved communities toward the "research establishment." Grassroots partners in dicated that they were accustomed to researchers "dropping in for a touch of color" and then leaving to meet their own unique academic needs. They expected that a partnership with the Beach Center would be one more such disappointing experience. Yet as our partnership grew over the years, we learned about each other's worlds, and we discovered insights and innovations that would have been impossible from homogeneous vantage points. In time, we all realized the mutual benefits of the partnership--for each of us as partners and more importantly for the families as beneficiaries of our collaborative efforts. The key factor, however, that we would underscore that has made the most difference in the quality of our partnership was being upfront and "out on the table" from the outset about our visions, suspicions, fears, and hopes. As we have reflected as a group about our partnership experience, we came up with 12 lessons we have learned that we believe form the foundation for our reliable alliance. These principles, highlighted in Table 1, are clearly consistent with the findings of Lamb-Parker et al. in terms of attributes that are related to a high degree of shared decision making.

Table 1. Lessons Learned From the Beach Center Grassroots Consortium on Disabilities Partnership

1. We created opportunities for sharing family and professional stories and getting to know one another as people.

2. The mailings that went out from the Beach Center after the initial retreat helped to maintain the progress made at that retreat. With each subsequent mailing, members of the Grassroots Consortium on Disabilities had more reason to believe that the Beach Center had not just dropped in "for a touch of color."

(Table 1. continued on next page) 
3. Planning specific activities to undertake together brought to the surface issues that might otherwise have remained submerged. These issues could then be dealt with as they arose. The early grant writing venture helped us to understand more clearly our respective contexts, as well as our own differing paces for addressing issues and taking action.

4. We committed ourselves to open and honest dialogue about our participatory action research process and its promises and pitfalls.

5. We recognized and affirmed the strengths and perspectives that each team member brings to the table and developed roles that take full advantage of these diverse contributions.

6. We worked to understand the contexts and realities of each of The partners and recognize that our progress as a team may be slower as a result of these realities.

7. We allowed each partner time to involve all of its members fully in discussions about our partnership so that decisions were made with full participation and information.

8. We recognized that not all activities can equally benefit both partners all the time.

9. We identified a leadership team for each organization and a single point to contact for each organization. The leadership teams hold conference calls and/or faceto-face meetings to revisit our shared vision, define critical issues, determine priorities, and outline action plans. Each leadership team shares information about these discussions with the wider membership of its organization and solicits input. Input from the membership may mean that additional conversations are needed between the leadership teams. As decisions are made, each leadership team is responsible for follow-up activities.

10. Having developed a basis for trust, a belief in good intentions, and a commitment to the partnership, we weathered and learned from the "Oops" factors. We identified and corrected mistakes that were made of inexperience and misperceptions.

11. By acknowledging that our efforts to break new ground came with possible risks for each partner as well, we strengthened our relationship and underscored our commitments to each other.

12. We continually nurtured and refined our partnerships and the relationships within them. The process of partnering evolves and changes with each venture and requires time to assure the quality of the partnership as well as its joint activities (Santelli et al., 2001). 
As we noted, Lamb-Parker's study leads to the conclusion that the intensive effort required to build an effective partnership is well worth it. The next step for research about partnership formation is further study to determine whether there are lasting outcomes to the development of partnerships that are characterized by the qualities and the interim outcomes Lamb-Parker et al. describe. More longitudinal study will be needed to learn whether partnerships with shared decision making produce enhanced long-term outcomes. That is, does research reach a higher standard of rigor (measured by the quality of final reports and acceptance in peer-reviewed journals) when conducted in an atmosphere of shared decision making? Does research conducted in an atmosphere of shared decision making produce results that are more easily incorporated into practice and produce lasting change in services? And finally, the bottom line, does research conducted by meaningful partnerships produce positive results in child and family quality of life?

Some years ago, one of the authors of this commentary was involved as part of a parent-professional team delivering in-service training about family issues to a number of professional audiences. As the professional member of the training team, she would often field questions by saying, "The research says ..." The parent member of the team would then respond, "Well, the research says that, but it's also true." The lesson this researcher carried away from that partnership is that "truth" means different things to different people. For researchers and policy makers, "truth" may mean empirically derived and tested results. For practitioners, "truth" may be visible evidence in the form of change and growth when a given practice is used. For parents, "truth" may be a sense of resonance or a "ringing true" with the experience of everyday life. Perhaps, for "truth" to be accepted and utilized to improve lives of children and families, it must be all of these things. As we reflect on our own research partnership, we believe this "triple truth" is in the process of coming to fruition. We are delighted to finally have evidence that what is "truth" according to our practice and our life, experiences is also "true" according to research.

\section{REFERENC ES}

Markey, U., Santelli, B., \& Turnbull, A. P. (1998). Participatory action research involving families from underserved communities and researchers: Respecting cultural and linguistic diversity. In B. A. Ford (Ed.), Compendium: Writings on effective practice for culturally and linguistically diverse exceptional learners. Reston, VA: Council for Exceptional Children, Division for Culturally and Linguistically Diverse Exceptional Learners.

Santelli, B., Markey, U., Johnson, A., Turnbull, R., \& Turnbull, A. (2001). The evolution of an unlikely partnership between researchers and culturally diverse families: Lessons learned. TASH Newsletter, March/April.

Turnbull, A. P., Friesen, B. J., \& Ramirez, C. (1998). Participatory action research as a model of conducting family research. Journal of The Association for Persons with Severe Handicaps, 23(3), 178-188. 
